\title{
Genome analysis leads to discovery of Quorum Sensing Genes in Cedecea neteri
}

3 Kian-Hin $\operatorname{Tan}^{1}$ and Kok-Gan $\operatorname{Chan}^{1}$ *

$4 \quad{ }^{1}$ Division of Genetics and Molecular Biology, Institute of Biological Sciences, Faculty of Science,

5 University of Malaya, 50603 Kuala Lumpur, Malaysia

* Correspondence: Kok-Gan Chan, Division of Genetics and Molecular Biology, Institute of

7 Biological Sciences, Faculty of Science, University of Malaya, 50603 Kuala Lumpur, Malaysia.

8 kokgan@um.edu.my

\section{Abstract}

11 We have identified a strain of $C$. neteri SSMD04 isolated from pickled mackerel sashimi that

12 produced $N$-acyl-homoserine lactone (AHL) type quorum sensing (QS) activity. Tandem mass sspectrometry revealed that $C$. neteri SSMD04 produced $N$-butyryl-homoserine lactone (C4-HSL). We identified a pair of luxIR homologues in this genome that shares the highest similarity with croIR from Citrobacter rodentium. The AHL synthase, which we named it as cneI (636 bp) and at 8bp distance from cneI is a sequence encoding a hypothetical protein, potentially the cognate receptor, a $\operatorname{lux} R$ homologue which we named it as cneR. We also found an orphan luxR in this isolate. To our knowledge, this is the first report on the AHL production activity in C. neteri, discovery of its $\operatorname{luxI} / R$ homologues and the orphan receptor.

\section{Introduction}

22 Cedecea spp. are extremely rare Gram-negative bacteria that belong to the Enterobacteriaceae family (Berman, 2012). This genus is lipase-positive and resistant to colistin and cephalothin. The name

24 Cedecea was coined by P. A. D. Grimont and F. Grimont, from the abbreviation of the Centers for 25 Disease Control (CDC) (Grimont, Grimont \& Farmer, 1981). Originally recognized as Enteric group 15 , this genus is comprised of five species, out of which only three were named, $C$. neteri, $C$. 
lapagei, C. davisae, and the other two are known as Cedecea species 3 and Cedecea species 5

(Brenner et al., 2005).

Cedecea species 4 was given the name C. neteri in 1982 when its clinical significance was reported.

The name 'neteri' was coined to honor Erwin Neter, an American physician-microbiologist for his contributions in the work on Enterobacteriaceae in human disease (Farmer III et al., 1982). C. neteri was also found in a patient with systemic lupus erythematosus where it led to the patient's death (Aguilera et al., 1995). Even though it was evident that $C$. neteri can act as human pathogen, its etiology is unknown and limited studies have been conducted on Cedecea spp. There were cases of isolation of Cedecea spp. from other sources except human (Jang \& Nishijima, 1990; Osterblad et al., 1999), and we have recently reported the isolation of C. neteri SSMD04 from Shime saba (Chan et al., 2014), a Japanese cuisine that involves marinating with salt and rice vinegar, enabling the usually perishable saba (mackerel) to be enjoyed in the form of Sashimi (raw fish).

Bacteria demonstrate a concerted gene regulation mechanism termed 'Quorum Sensing' (QS) that relies on the population density of the bacteria (Fuqua, Winans \& Greenberg, 1996; Miller \& Bassler, 2001; Schauder \& Bassler, 2001). The mechanism of QS involves the production, release, detection, and response to small diffusible molecules known as autoinducers, such as $N$-acyl homoserine lactones (AHLs) commonly employed by Gram negative bacteria (Chhabra et al., 2005; Williams et al., 2007). AHL molecules are generally characterized by the length and saturation of its acyl side chains which can vary from 4 to 18 carbons (Pearson, Van Delden \& Iglewski, 1999), as well as the 2005). QS has been shown to play a role in the regulation of a wide range of phenotypes, such as antibiotic biosynthesis, biofilm formation, pathogenesis, bioluminescence, antibiotic production and

\subsection{Sample collection and processing}


Shime saba sashimi sample was collected from a local supermarket in Malaysia and processed within half an hour following collection. Five grams of sample was stomached and homogenized in $50 \mathrm{ml}$ of peptone water and then spread on MacConkey (MAC) agar. The culture plates were incubated overnight in $28^{\circ} \mathrm{C}$.

\subsection{Bacterial strains, media and culture conditions}

C. neteri SSMD04, Chromobacterium violaceum CV026, Erwinia carotovora GS101 and E. broth cultures were incubated with shaking (220 rpm).

\subsection{Species identification of isolate SSMD04}

\subsubsection{S rDNA phylogenetic analysis}

16S rDNA sequence was extracted from the complete genome sequence of isolate SSMD04, while other 16S rDNA sequences of Cedecea. spp. were retrieved from GenBank. The Molecular Evolutionary Genetics Analysis (MEGA) 6.0 (Tamura et al., 2013) was used to align the sequences and construct a Maximum likelihood tree using 1,000 bootstrap replications.

\subsubsection{Biolog GEN III microbial identification system}

Microbial identification using Biolog GEN III MicroPlate ${ }^{\mathrm{TM}}$ was carried out according to manufacturer's protocol. In brief, overnight culture of C. neteri SSMD04 grown on Tryptic Soy Agar (TSA) was used to inoculate inoculating fluid (IF) A to a cell density of 90-98\% transmittance. The inoculum was then pipetted into each well of the MicroPlate $^{\mathrm{TM}}(100 \mu \mathrm{L}$ per well) and incubated at 28 ${ }^{\circ} \mathrm{C}$ for $24 \mathrm{hrs}$. The MicroPlate was then read using Biolog's Microbial Identification Systems software where the wells will be scored as 'negative' or 'positive' based on the colour change due to the reduction of tetrazolium redox dyes. This 'Phenotypic Fingerprint' was then used to identify the bacteria by matching it against the database in the system. 


\subsection{Detection of AHL production in C. neteri SSMD04}

85 AHL-type QS activity of C. neteri SSMD04 was screened using biosensor C. violaceum CV026. This 86 is performed by cross streaking $C$. neteri SSMD04 against C. violaceum CV026. E. carotovora

87 GS101 and E. carotovora PNP22 were used as positive and negative controls, respestively (McClean 88 et al., 1997).

\subsection{AHL extraction}

C. neteri SSMD04 was cultured overnight at $28{ }^{\circ} \mathrm{C}$ in LB broth $(100 \mathrm{~mL})$ supplemented with $50 \mathrm{mM}$ of 3-(N-morpholino)propanesulfonic acid (MOPS) (pH5.5). Spent supernatant was collected by centrifugation and subsequently extracted twice with equal volume of acidified ethyl acetate (AEA) $(0.1 \% \mathrm{v} / \mathrm{v}$ glacial acetic acid). The extracts were air dried and reconstituted in $1 \mathrm{~mL}$ of AEA, transferred into sterile microcentrifuge tubes and air dried again, before being stored at $-20{ }^{0} \mathrm{C}$. The extracts were later used for detection of AHL by lux-based biosensor E. coli [pSB401] as well as triple quadrupole LC/MS.

\subsection{AHL identification by triple quadrupole LC/MS}

100 Extracts from section 2.5 were reconstituted in acetonitrile (ACN) prior to LC/MS analysis as described before (Lau et al., 2013) with slight modification. In brief, mobile phase A used was water with $0.1 \% \mathrm{v} / \mathrm{v}$ formic acid and mobile phase B used was ACN with $0.1 \%$ formic acid. The flow rate used was $0.5 \mathrm{~mL} / \mathrm{min}$. The gradient profile was set to: A:B 80:20 at $0 \mathrm{~min}, 50: 50$ at $7 \mathrm{~min}, 50: 50$ at scan mode was carried out in positive ion mode with Q1 set to monitor $m / z 90$ to $m / z 400$ and Q3 set to monitor for $m / z$ 102. ACN was also used as a blank. 
109

110

111

112

113

114

115

116

117

118

119

120

121

122

123 3. Results

124

125

126

127

128

129

E. coli [pSB401] (Winson et al., 1998) was used as biosensor for the detection of exogenous short chain AHLs present in the extracts. The biosensor strain was cultured in LB broth supplemented with tetracycline $(20 \mu \mathrm{g} / \mathrm{mL})$. The overnight culture was then diluted to an $\mathrm{OD}_{600}$ of 0.1 with fresh $\mathrm{LB}$ broth with tetracycline. The diluted $E$. coli culture was used to resuspend the extracts from section 2.5 , prior to being dispensed into a 96-well optical bottom microtitre plate. Cell density bioluminescence measurements were carried out by Infinite M200 luminometer-spectrophotometer (Tecan, Männedorf, Switzerland) over a period of 24 hours. Diluted E. coli culture without extracts was read for normalization and sterile broth was used as negative control. The results were displayed as relative light units (RLU)/OD495 nm against incubation time.

\subsection{Genome annotation and analysis}

Whole genome of $C$. neteri SSMD04 was annotated by RAST as described (Chan et al., 2014). DNAPlotter (Carver et al., 2009) was used to construct GC plot and GC skew.

\subsection{Species identification of $C$. neteri SSMD04}

16S rDNA sequence retrieved from whole genome sequence of $C$. neteri SSMD04 was used to construct a phylogenetic tree with other sequences of Cedecea spp. available in GenBank. 16S rDNA sequence of $C$. neteri SSMD04 clusters with other $C$. neteri strains in a monophyletic clade (Figure 1). However, it can also be observed that the available $16 \mathrm{~S}$ rDNA sequences of $C$. davisae formed two distinct clusters, of which one is more closely related to C. neteri and the other C. lapagei. 


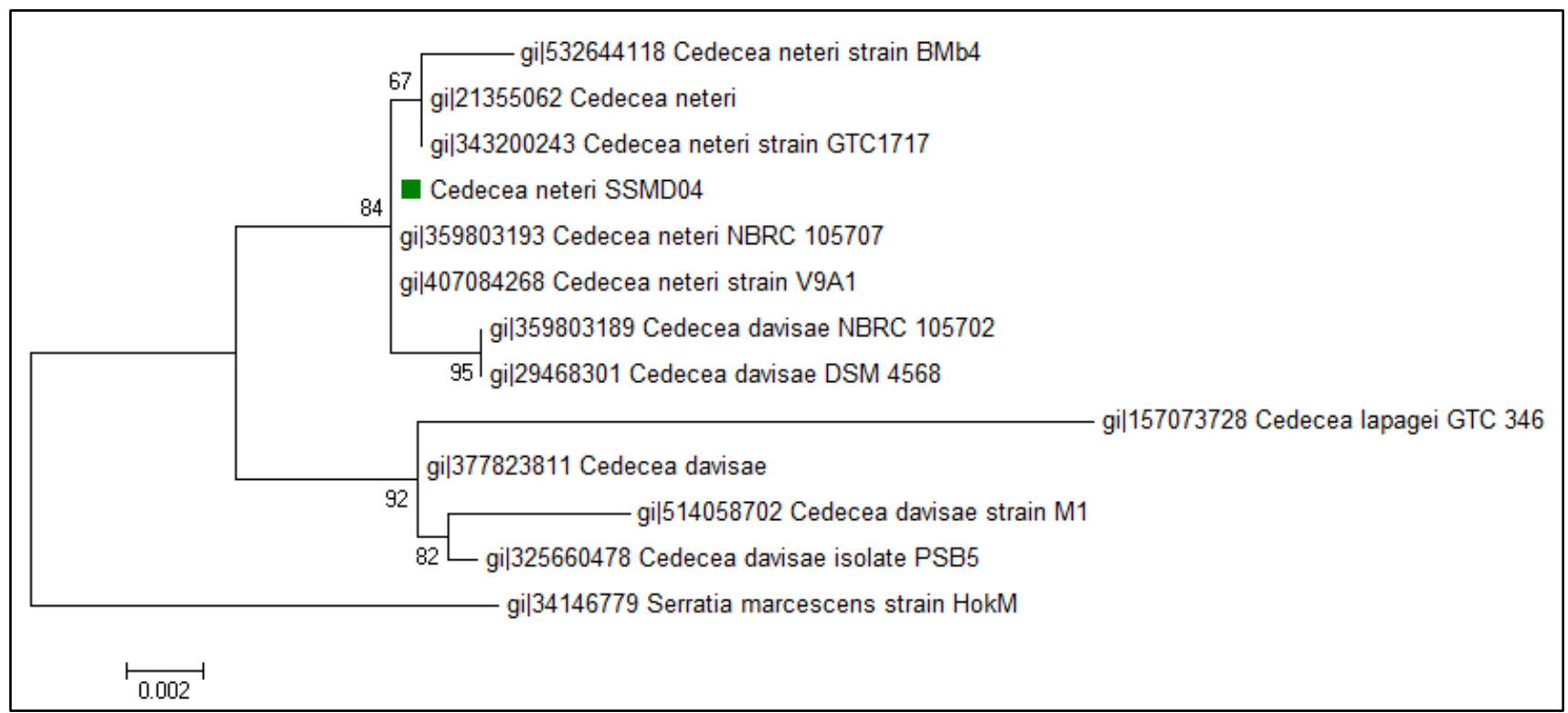

Figure 1. Phylogenetic tree showing the position of C. neteri SSMD04 (green square) relative to other Cedecea spp. The neighbour joining tree was inferred from 1,297 aligned positions of the 16S rDNA sequences using Hasegawa-Kishino-Yano substitution model. Boostrap values are represented at the branch point. The scale denotes the number of substitutions per nucleotide position. Serratia marcescens strain HokM was used as an outgroup.

Biology Gen III microbial identification system was also used to assess the identity of $C$. neteri Farmer III et al., 1982.

\subsection{Detection of AHL-type QS activity in $C$. neteri SSMD04 using AHL biosensor} produced from $C$. neteri SSMD04 diffused passively towards the biosensor, activating the production of purple colour pigment, violacein. The result shown in Figure 2 indicated the presence of exogenous AHLs in C. neteri SSMD04 culture. 


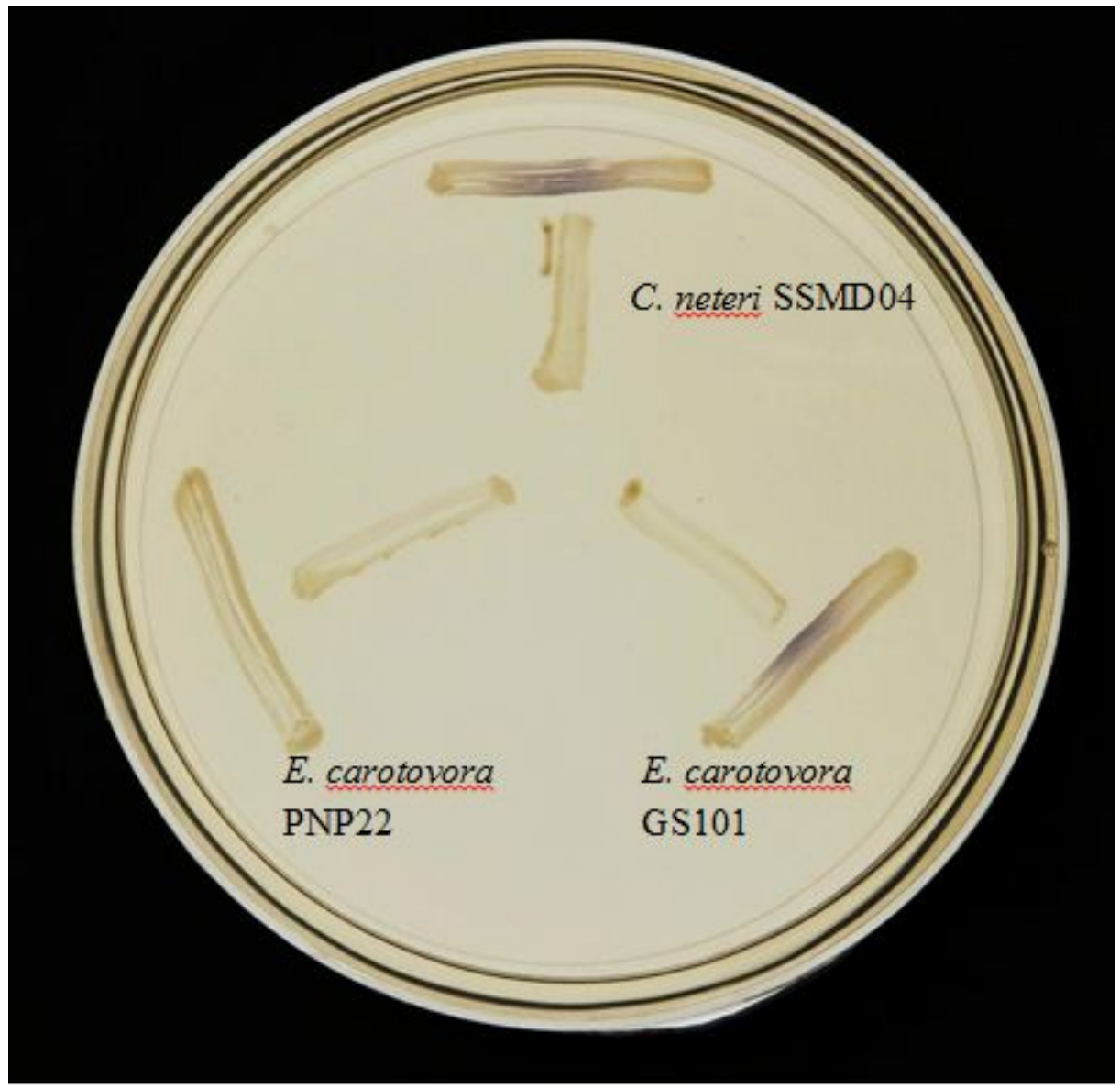

148 Figure 2. Screening for AHL-type QS activity of $C$. neteri SSMD04 using the biosensor $C$.

149 violaceum CV026. E. carotovora PNP22 and E. carotovora GS101 act as negative and positive 150 controls, respectively.

\subsection{Measurement of bioluminescence}

153 C. neteri SSMD04 also activated lux-based biosensor E. coli [pSB401] which produces

154 bioluminescence in the presence of short chain AHLs (Figure 3). 


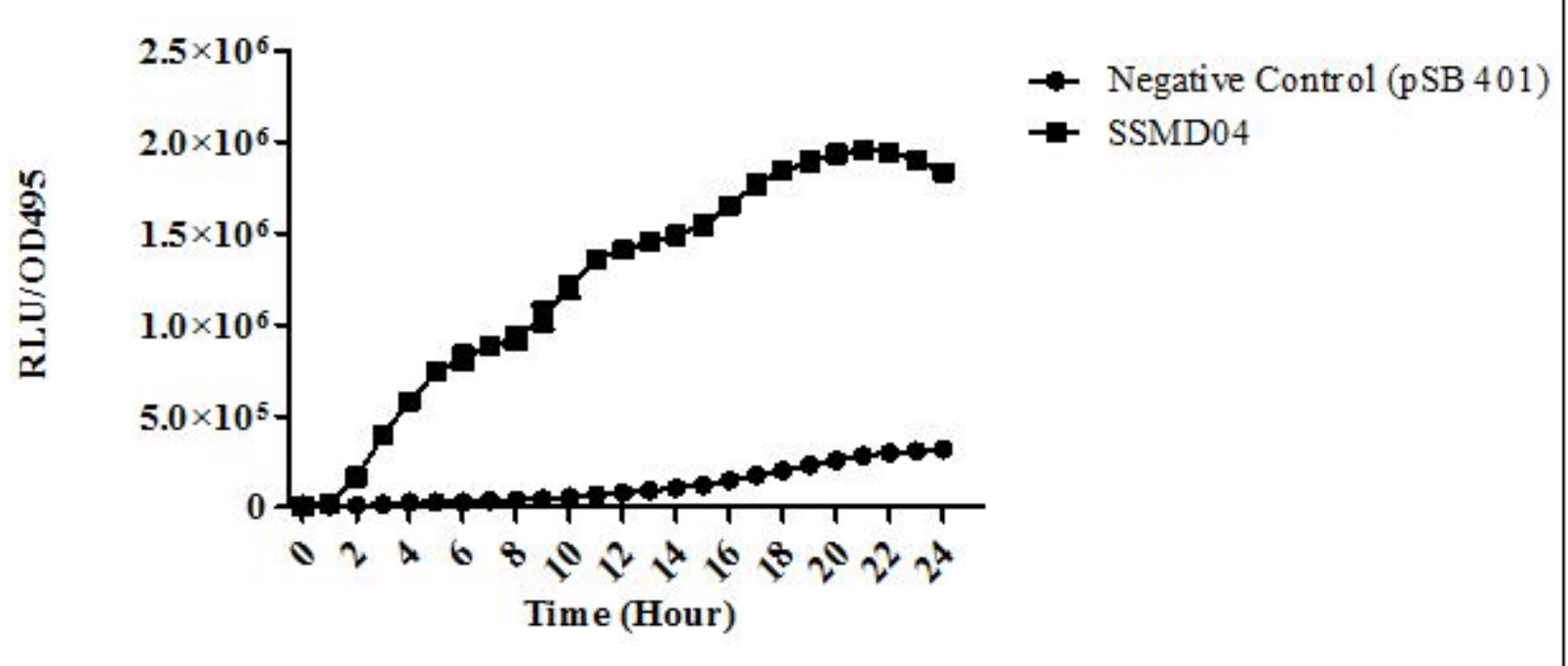

156 Figure 3. Relative light unit (RLU)/OD495 against incubation time of cultures of E. coli [pSB401] in 157 the presence of extracted AHLs (square plots) and negative control (circle plots).

\subsection{AHL identification by triple quadrupole LC/MS}

160 The extracted-ion chromatogram (EIC) generated from the triple quadrupole LC/MS system showed 161 a peak with the same retention time as that of the synthetic $N$-butyryl-homoserine lactone (C4-HSL) 162 standard, which was constantly present in all three replicates (Figure 4). Analysis of the mass 163 spectrum (MS) data revealed the presence of a peak with mass-to-charge ratio $(\mathrm{m} / \mathrm{z})$ of 172 (Figure 164 5), which is consistent with the previously reported value (Ortori et al., 2011). This implication was 165 strengthened by the presence of a product ion peak $(m / z=102)$. 
Figure 4. EIC of $C$. neteri SSMD04 extract. The data represented three replicates of the extract against synthetic C4-HSL. ACN was used as blank.

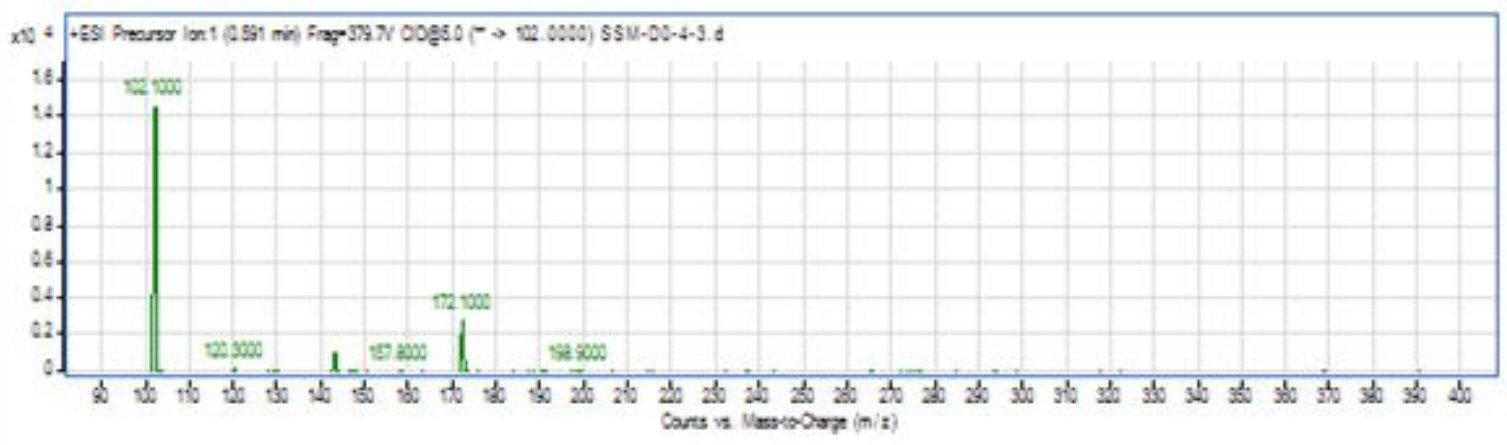

171 Figure 5. Product ions of the peak seen in Figure 4. This shows that the extract of C. neteri SSMD04 172 contains C4-HSL.

\section{$174 \quad 3.5 \quad$ Genome annotation and analysis}

175 As reported previously, the whole genome sequence of $C$. neteri SSMD04 was annotated by RAST

176 (Aziz et al., 2012) (Figure 6). Figure 7 shows the visualization of C. neteri SSMD04 genome. From

177 the data generated by NCBI prokaryotic genome annotation pipeline, a 636 bp luxI homologue, 
hereafter named cneI, was found in the genome. This gene shares $70 \%$ base pair similarity with $N$ acyl homoserine lactone synthase croI of Citrobacter rodentium ICC168. Analysis of amino acid sequence of cneI using InterPro (Mitchell et al., 2015) identified the presence of an acyl-CoA- $N$ acyltransferase, the structural domain of $N$-acyl homoserine lactone synthetases (Gould, Schweizer and Churchill, 2004; Watson et al., 2002).

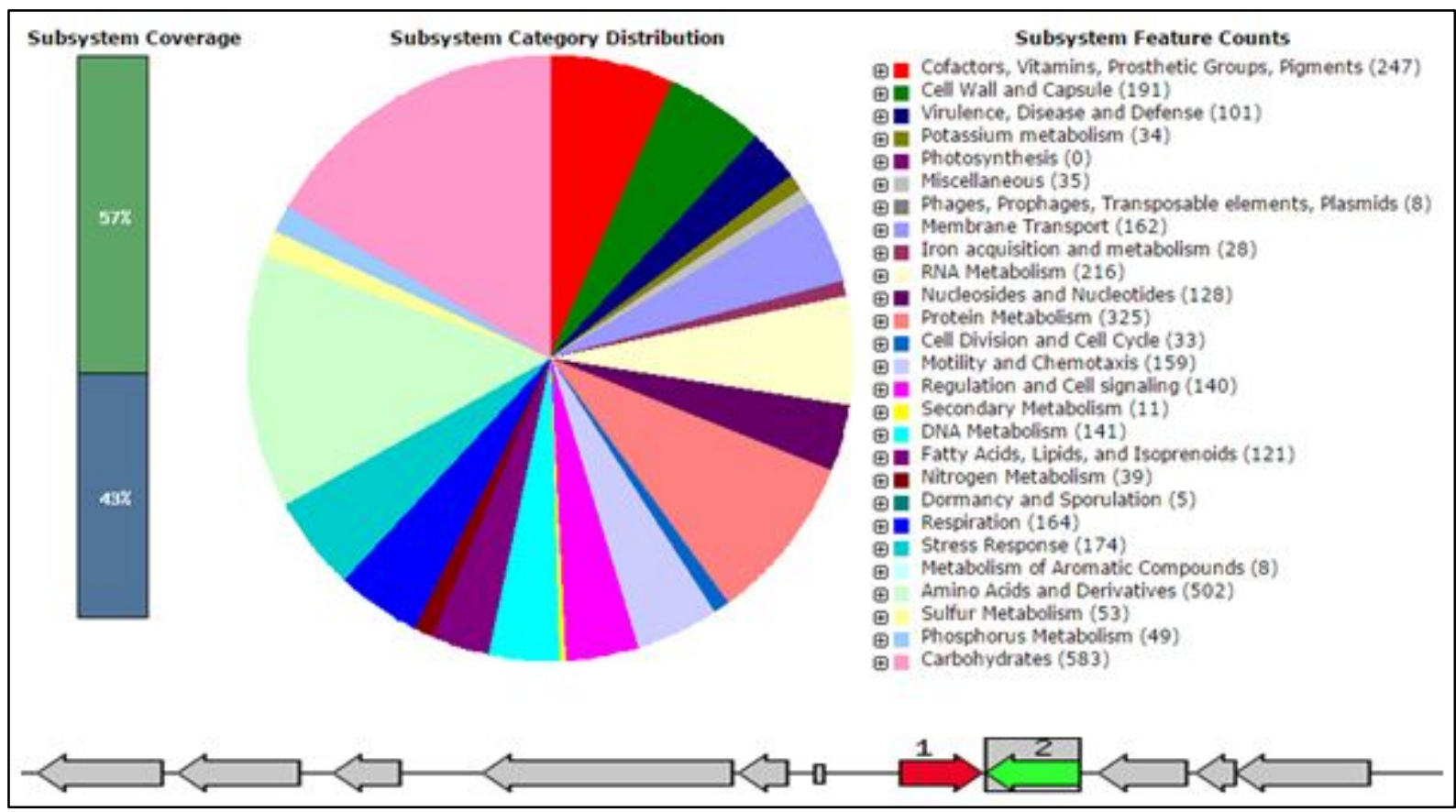

Figure 6. From left to right: Alkanesulfonate utilization operon LysR-family regulator Cbl; Nitrogen assimilation regulatory protein Nac; Membrane protein, suppressor for copper-sensitivity ScsD; Membrane protein, suppressor for copper-sensitivity ScsB; Suppression of copper sensitivity: putative copper binding protein ScsA; tRNA-Asn-GTT; LuxI homologue protein; LuxR homologue protein; Bifunctional protein: zinc-containing alcohol dehydrogenase/ quinone oxidoreducatse (NADPH: quinone reductase).

Adjacent to cneI, 8 bp away, is a sequence encoding a hypothetical protein, potentially the cognate receptor, a luxR homologue (cneR). The coding region was found to be $705 \mathrm{bp}$ long and share $70 \%$ similarity with $\operatorname{croR}$ of $C$. rodentium. Analysis of this protein reveals two signature domains, the autoinducer-binding domain and the C-terminal effector. 


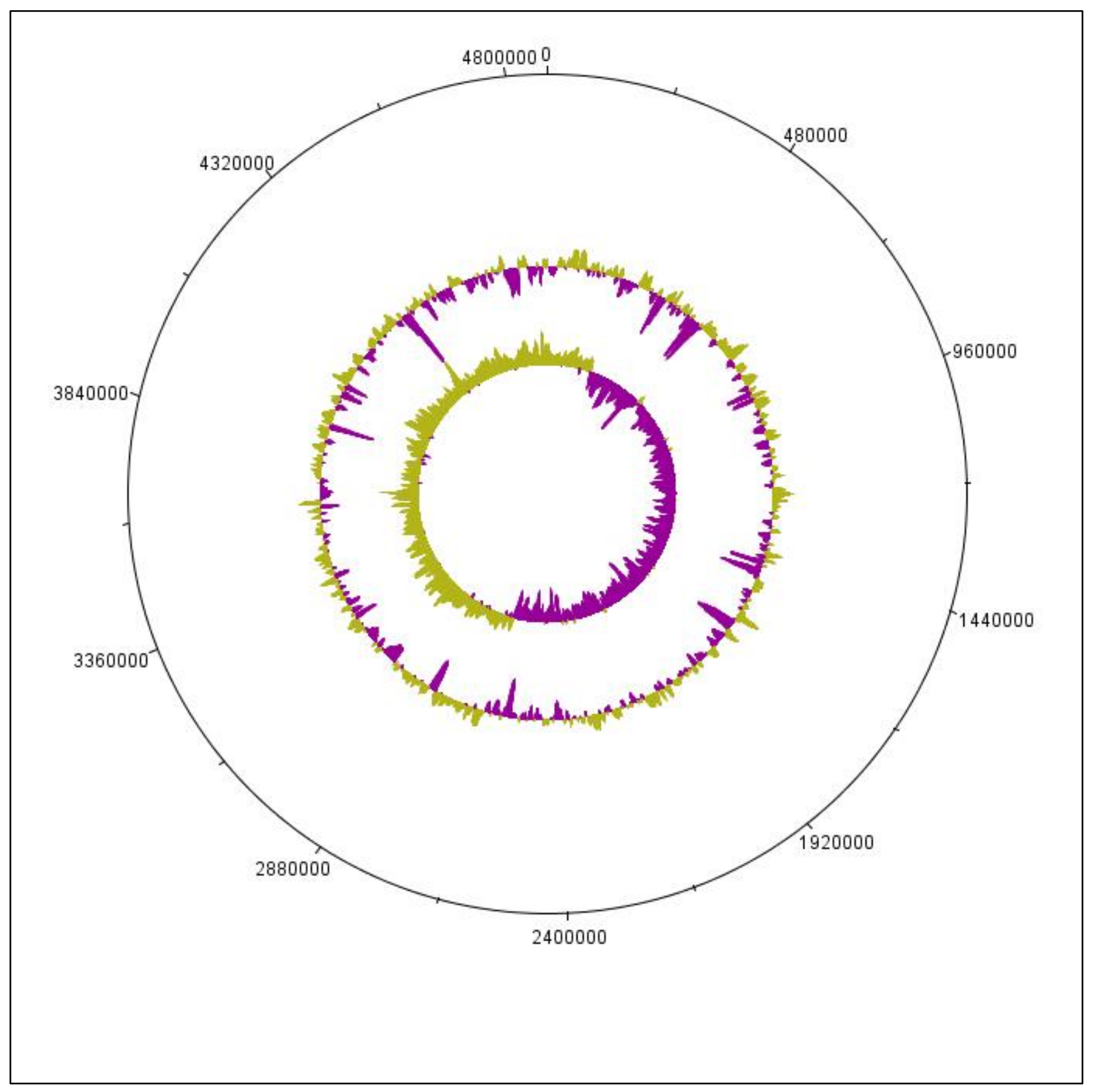

197 Figure 7. Whole genome representation of C. neteri SSMD04 genome using DNAplotter. The 198 number on the outermost circle is the scale for the plot. The innermost circle represents GC skew, while the second circle represents GC content. 
201

202

203

204

205

206

207

208

209

210

211

212

213

214

215

216

217

218

219

220

221

222

223

224

225

226

227

228

229

Apart from that, a sequence potentially encoding an orphan luxR type receptor (723 bp) was also found within the genome. This luxR homologue shares $69 \%$ sequence homology to luxR homologue of Enterobacter asburiae L1.

\section{Discussion}

Cedecea spp. are very rare bacteria and thus not well studied. Despite the evidence of their ability to infect human, their medical significance can be overlooked due the poor understanding of their physiology and etiology. Besides that, they are potentially challenging pathogens due to their resistance towards a wide range of antimicrobial agents, such as cephalothin, extended spectrum cephalosporins, colistin, and aminoglycosides (Mawardi et al., 2010; Abate, Qureshi \& Mazumder, 2011; Dalamaga et al., 2008). To date, isolation of this species from non-clinical source has not been reported. Therefore, the isolation of $C$. neteri SSMD04 from a food source expands the current knowledge on diversity of the genus Cedecea.

Although employed by a wide range of Gram-negative bacteria in gene regulation that allows the alteration of behaviour on a population level (Waters \& Basslers, 2005), AHL-type QS activities have not been reported in C. neteri. Some bacteria utilizes QS to regulate virulence and thus gaining advantage of expressing virulence factors only when the population density is large enough to triumph the hosts' immune system (Passador et al., 1993; Brint \& Ohman, 1995; McClean et al., 1997; Thomson et al., 2000; Weeks et al., 2010). Given the understanding that $C$. neteri can act as human pathogen, it can be hypothesized that AHL-type QS activity in C. neteri is involved in the regulation of virulence factors. However, further studies on clinical as well as non-clinical strains would help in the solution of this hypothesis.

The whole genome sequence provides very valuable information in studying the genetic basis of QS in C. neteri SSMD04. The finding of cneIR in this genome, lying adjacent to each other, demonstrated a common feature of luxIR homologues (Brint \& Ohman, 1995; Fuqua, Winans \& Greenberg, 1994; Williamson et al., 2005). Analysis of amino acid sequence of the cneIR pair with InterPro agreed with their identity. The cneIR pair was found to be most similar to croIR in $C$. 
230

231

232

233

234

235

236

237

238

239

240

241

242

243

244

245

246

247

248

249

rodentium. C. rodentium has been found to produce C4-HSL as the major AHL and C6-HSL as the minor (Coulthurst et al., 2007). C. neteri SSMD04 also produces C4-HSL, but it does not produce detectable level of C6.

The presence of lipase-positive $C$. neteri in marinated oily fish strongly suggests its role as a potential food spoilage agent, not only because of its ability to survive an extreme environment of high salinity and acidity, but also the fact that AHLs have long been associated with food spoilage via regulation of the proteolytic and lipolytic pathways (Skandamis \& Nychas, 2012; Bruhn et al., 2004). Nevertheless, the roles of $C$. neteri in pathogenesis and food spoilage still require more information to be elucidated.

\section{Conclusion}

This study has confirmed the production of C4-HSL by C. neteri SSMD04 isolated from Shime saba sashimi. This is the first report of QS activity in C. neteri. However, the function of QS in C. neteri SSMD04 is still unknown. We hope that further studies coupled with the available genome information of $C$. neteri SSMD04 can help to elucidate the regulatory circuit of $C$. neteri SSMD04 by QS.

\section{References}

Abate G, Qureshi S, and Mazumder SA. 2011. Cedecea davisae bacteremia in a neutropenic patient with acute myeloid leukemia. $J$ Infect 63:83-85.

Aziz RK, Devoid S, Disz T, Edwards RA, Henry CS, Olsen GJ, Olson R, Overbeek R, Parrello B, Pusch GD, Stevens RL, Vonstein V, and Xia F. 2012. SEED servers: high-performance access to the SEED genomes, annotations, and metabolic models. PLoS One 7:e48053.

Bainton NJ, Stead P, Chhabra SR, Bycroft BW, Salmond GP, Stewart GS, and Williams P. 1992. N(3-oxohexanoyl)-L-homoserine lactone regulates carbapenem antibiotic production in Erwinia carotovora. Biochem J 288 ( Pt 3):997-1004.

Berman JJ. 2012. Taxonomic guide to infectious diseases: understanding the biologic classes of pathogenic organisms. Academic Press. 
Brenner DJ, Krieg NR, Staley JT, Garrity GM. 2005. Bergey's manual of systematic bacteriology, vol. 2. The Proteobacteria, East Lansing, USA, 183.

Brint JM, and Ohman DE. 1995. Synthesis of multiple exoproducts in Pseudomonas aeruginosa is under the control of RhlR-RhlI, another set of regulators in strain PAO1 with homology to the autoinducer-responsive LuxR-LuxI family. J Bacteriol 177:7155-7163.

Bruhn JB, Christensen AB, Flodgaard LR, Nielsen KF, Larsen TO, Givskov M, and Gram L. 2004. Presence of acylated homoserine lactones (AHLs) and AHL-producing bacteria in meat and potential role of AHL in spoilage of meat. Appl Environ Microbiol 70:4293-4302.

Carver T, Thomson N, Bleasby A, Berriman M, and Parkhill J. 2009. DNAPlotter: circular and linear interactive genome visualization. Bioinformatics 25:119-120.

Chan KG, Tan KH, Yin WF, and Tan JY. 2014. Complete genome sequence of Cedecea neteri strain SSMD04, a bacterium isolated from pickled mackerel sashimi. Genome Announc 2.

Chhabra SR, Philipp B, Eberl L, Givskov M, Williams P, and Camara M. 2005. Extracellular communication in bacteria. Chemistry of Pheromones and Other Semiochemicals II 240:279315.

Coulthurst SJ, Clare S, Evans TJ, Foulds IJ, Roberts KJ, Welch M, Dougan G, and Salmond GP. 2007. Quorum sensing has an unexpected role in virulence in the model pathogen Citrobacter rodentium. EMBO Rep 8:698-703.

Dalamaga M, Karmaniolas K, Arsenis G, Pantelaki M, Daskalopoulou K, Papadavid E, and Migdalis I. 2008. Cedecea lapagei bacteremia following cement-related chemical burn injury. Burns 34:1205-1207.

de Kievit TR, and Iglewski BH. 2000. Bacterial quorum sensing in pathogenic relationships. Infect Immun 68:4839-4849.

Eberl L, Winson MK, Sternberg C, Stewart GS, Christiansen G, Chhabra SR, Bycroft B, Williams P, Molin S, and Givskov M. 1996. Involvement of $N$-acyl-L-hormoserine lactone autoinducers in controlling the multicellular behaviour of Serratia liquefaciens. Mol Microbiol 20:127-136.

Farmer JJ, 3rd, Sheth NK, Hudzinski JA, Rose HD, and Asbury MF. 1982. Bacteremia due to Cedecea neteri sp. nov. J Clin Microbiol 16:775-778.

Fuqua C, Winans SC, and Greenberg EP. 1996. Census and consensus in bacterial ecosystems: the LuxR-LuxI family of quorum-sensing transcriptional regulators. Annu Rev Microbiol 50:727751.

Gould TA, Schweizer HP, and Churchill ME. 2004. Structure of the Pseudomonas aeruginosa acylhomoserinelactone synthase LasI. Mol Microbiol 53:1135-1146. 
Grimont PAD, Grimont F, Farmer JJ, 3rd, Asbury MA. 1981. Cedecea davisae gen. nov., sp. nov. and Cedecea lapagei sp. nov., New Enterobacteriaceae from clinical specimens. Int. J. Syst. Bacteriol. 31:317-326.

Hastings JW, and Nealson KH. 1977. Bacterial bioluminescence. Annu Rev Microbiol 31:549-595. Hao Y, Winans SC, Glick BR, and Charles TC. 2010. Identification and characterization of new LuxR/LuxI-type quorum sensing systems from metagenomic libraries. Environ Microbiol 12:105-117.

Jang EB and Nishijima KA. 1990. Identification and attractancy of bacteria associated with Dacus dorsalis (Diptera: Tephritidae). Environm. Entomol. 19:1726-1731.

Lau YY, Sulaiman J, Chen JW, Yin WF, and Chan KG. 2013. Quorum sensing activity of Enterobacter asburiae isolated from lettuce leaves. Sensors (Basel) 13:14189-14199.

Mawardi H, Pavlakis M, Mandelbrot D, and Woo SB. 2010. Sirolimus oral ulcer with Cedecea davisae superinfection. Transpl Infect Dis 12:446-450.

McClean KH, Winson MK, Fish L, Taylor A, Chhabra SR, Camara M, Daykin M, Lamb JH, Swift S, Bycroft BW, Stewart GS, and Williams P. 1997. Quorum sensing and Chromobacterium violaceum: exploitation of violacein production and inhibition for the detection of $\mathrm{N}$ acylhomoserine lactones. Microbiology 143 ( Pt 12):3703-3711.

Miller MB, and Bassler BL. 2001. Quorum sensing in bacteria. Annu Rev Microbiol 55:165-199. Mitchell A, Chang HY, Daugherty L, Fraser M, Hunter S, Lopez R, McAnulla C, McMenamin C, Nuka G, Pesseat S, Sangrador-Vegas A, Scheremetjew M, Rato C, Yong SY, Bateman A, Punta M, Attwood TK, Sigrist CJ, Redaschi N, Rivoire C, Xenarios I, Kahn D, Guyot D, Bork P, Letunic I, Gough J, Oates M, Haft D, Huang H, Natale DA, Wu CH, Orengo C, Sillitoe I, Mi H, Thomas PD, and Finn RD. 2015. The InterPro protein families database: the classification resource after 15 years. Nucleic Acids Res 43:D213-221.

Ortori CA, Dubern JF, Chhabra SR, Camara M, Hardie K, Williams P, and Barrett DA. 2011. Simultaneous quantitative profiling of $N$-acyl-L-homoserine lactone and 2-alkyl-4(1H)quinolone families of quorum-sensing signaling molecules using LC-MS/MS. Anal Bioanal Chem 399:839-850.

Osterblad M, Pensala O, Peterzens M, Heleniusc H, and Huovinen P. 1999. Antimicrobial susceptibility of Enterobacteriaceae isolated from vegetables. J Antimicrob Chemother 43:503-509.

Passador L, Cook JM, Gambello MJ, Rust L, and Iglewski BH. 1993. Expression of Pseudomonas aeruginosa virulence genes requires cell-to-cell communication. Science 260:1127-1130. 
Pearson JP, Van Delden C, and Iglewski BH. 1999. Active efflux and diffusion are involved in transport of Pseudomonas aeruginosa cell-to-cell signals. J Bacteriol 181:1203-1210.

Salmond GP, Bycroft BW, Stewart GS, and Williams P. 1995. The bacterial 'enigma': cracking the code of cell-cell communication. Mol Microbiol 16:615-624.

Schauder S, and Bassler BL. 2001. The languages of bacteria. Genes Dev 15:1468-1480.

Schauder S, Shokat K, Surette MG, and Bassler BL. 2001. The LuxS family of bacterial autoinducers: biosynthesis of a novel quorum-sensing signal molecule. Mol Microbiol 41:463-476.

Skandamis PN, and Nychas GJ. 2012. Quorum sensing in the context of food microbiology. Appl Environ Microbiol 78:5473-5482.

Tamura K, Stecher G, Peterson D, Filipski A, and Kumar S. 2013. MEGA6: Molecular Evolutionary Genetics Analysis version 6.0. Mol Biol Evol 30:2725-2729.

Thomson NR, Crow MA, McGowan SJ, Cox A, and Salmond GP. 2000. Biosynthesis of carbapenem antibiotic and prodigiosin pigment in Serratia is under quorum sensing control. $\mathrm{Mol}$ Microbiol 36:539-556.

Waters CM, and Bassler BL. 2005. Quorum sensing: cell-to-cell communication in bacteria. Annu Rev Cell Dev Biol 21:319-346.

Watson WT, Minogue TD, Val DL, von Bodman SB, and Churchill ME. 2002. Structural basis and specificity of acyl-homoserine lactone signal production in bacterial quorum sensing. $\mathrm{Mol}$ Cell 9:685-694.

Weeks JN, Galindo CL, Drake KL, Adams GL, Garner HR, and Ficht TA. 2010. Brucella melitensis $\mathrm{VjbR}$ and C12-HSL regulons: contributions of the $N$-dodecanoyl homoserine lactone signaling molecule and LuxR homologue VjbR to gene expression. BMC Microbiol 10:167.

Williams P, Winzer K, Chan WC, and Camara M. 2007. Look who's talking: communication and quorum sensing in the bacterial world. Philos Trans R Soc Lond B Biol Sci 362:1119-1134.

Williamson LL, Borlee BR, Schloss PD, Guan C, Allen HK, and Handelsman J. 2005. Intracellular screen to identify metagenomic clones that induce or inhibit a quorum-sensing biosensor. Appl Environ Microbiol 71:6335-6344.

Winson MK, Swift S, Fish L, Throup JP, Jorgensen F, Chhabra SR, Bycroft BW, Williams P, and Stewart GS. 1998. Construction and analysis of luxCDABE-based plasmid sensors for investigating $N$-acyl homoserine lactone-mediated quorum sensing. FEMS Microbiol Lett 163:185-192. 